\title{
APRENDIZAGEM COLABORATIVA EM AMBIENTES VIRTUAIS DE APRENDIZAGEM: A EXPERIÊNCIA INÉDITA DA PUCPR
}

\author{
E como poderei estar, meu Deus, nos lugares on de nunca estarei? \\ (Metamorfose, In: 33 Ciberpoemas, de Sérgio Caparelli) \\ Péricles Gomes VARELLA * \\ Sônia Cristina VERMELHO ** \\ Camile Golçalves HESKETH*** \\ Ana Carolina Castelli da SILVA****
}

\section{Resumo}

Este artigo é uma síntese dos resultados levantados e analisados, oriundos da experiência de institucionalização do Ambiente Virtual de Aprendizagem Eureka na Pontifícia Universidade Católica do Paraná. Tomando o Projeto Pedagógico da PUCPR, alicerçado na proposta da aprendizagem colaborativa, implementamos durante o ano de 2000 todo um conjunto de ações para incentivar o uso da tecnologia como suporte às atividades realizadas nas salas de aula. Tendo em vista os dados analisados, ainda que sejam os primeiros passos rumo a grandes transformações, evidenciou-se problemas que a educação presencial historicamente vivencia e procura superar. A tecnologia pode ser um suporte para essas mudanças, mas requer fundamentalmente uma mudança de postura e de enfrentamento da tecnologia e da metodologia que ela possa vir a suportar.

Palavras-chave: educação, tecnologias, prática educacional, aprendizagem.

\section{Résumé}

Ce texte est une synthèse des resultants de l'expérience de l'instauration de l' "Ambiente Virtual de Aprendizagem Eureka", de l'Université Catholique du Paraná. Ayant pour base le Projet Pédagogique de la PUCPR, qui se fonde sur le programme de l'apprentissage collaborative, nous avons mis en pratique pendant l'an 2000, un ensemble d'actions qui avaient pur but de stimuler l'usage des nouvelles technologies en tant qu'ínstruments capables d'auxilier les enseignants dans leur pratique pédagogique. Les données qui nous avons analysées, malgré le fait d'être encore rudimentaires, nous poussaient dans la direction de grandes transformations.

* Professor colaborador do Programa de Pós-Graduação em Educação da PUCPR. Email: pericles@ppgia.pucpr.br

** Doutoranda em educação pela PUCSP.

*** Núcleo de Tecnologias Educacionais da PUCPR.

* we*k Mestranda em Administração da PUCPR. 
Nous avons constaté de problèmes historiques que l'éducation presentielle cherche de résoudre sans succés. La technologie peut être un instrument de changement de la situation actuelle de la pratique éducative, mais cela exige une transformation de la mentalité des usagers des nouvelles technologies ainsi qu'un changement de leur pratique pédagogique.

Mots clés: éducation, technologies, pratique educative, apprentissage.

\section{Caminhosnovosemvelhoscaminhos}

A vida universitária, local de produção do conhecimento e de saberes, paradoxalmente engendrou os fundamentos para a sua própria superação. Neste século XXI, deparamo-nos com uma tensão que simboliza a metáfora da moeda: são duas faces distintas, mas indissociáveis: A universidade milenar da sociedade antiga e moderna e a universidade virtual da sociedade do conhecimento. São duas realidades aparentemente distintas que estão se confrontando mutuamente diante da introdução das tecnologias digitais na realidade educacional do ensino superior. A teia mundial de computadores, ou Internet, ou ciberespaço, que nasceu das salas de pesquisadores em universidades, tecnologia esta que tem como matéria-prima a informação, está sendo simbioticamente incorporada àquela universidade e transformando-a: é o movimento da dialética mostrando sua força e sua atualidade. No entanto, mais do que transformar o cotidiano das universidades porque nos proporciona acessos (quase) ilimitados às informações, alguns autores têm tratado de abordar o assunto sob outra perspectiva: a de que a experiência de participar da Cyberia pode "Indicar que nossa experiência com o ciberespaço não é técnica, mas é como se estivéssemos em um novo tipo de mundo social." (LYMAN, 1997, p. 120).

Pois, a tecnologia da Internet, que possibilitou o surgimento desse mundo virtual, da Cyberia, tem um “(...) extraordinário potencial (...) para catalisar a cooperação entre as pessoas e entidades que antes do advento das redes não tinham meios eficientes para se comunicarem ou para trabalharem em grupo" (SIMON, 1997, p. 9).

As atividades no ensino superior há muito pediam mudanças. Segundo BEHRENS (1999), trata-se de uma crise de paradigmas: de rompimento com o newtonianismo e o cartesianismo, com o ideal positivista, que levou as instituições formadoras, entre elas a própria universidade, a promover uma formação "(...) sectária, competitiva e individualista, que em nome da técnica e do capital, parece perder muito da função de buscar formar homens responsáveis, sensíveis e que venham a buscar o sentido da vida, do destino humano e de uma sociedade justa e igualitária". (p. 69) 
Neste movimento, a cooperação, a interação, a estrutura de rede se colocam na perspectiva de se tornarem as matrizes que irão fundamentar as práticas universitárias nestes novos tempos que se avizinham de nossas vidas no interior das instituições de ensino superior. Neste sentido, como afirma BEHRENS (1999), (...) o professor precisa repensar sua prática pedagógica, conscientizando-se de que não pode absorver todo o universo de informações e passar essas informações para seus alunos. (p. 70)

$E$, em função dessas mudanças, detecta que "um dos maiores impasses sofridos pelos docentes é justamente a dificuldade de ultrapassar a visão de que podia ensinar tudo aos estudantes." (BEHRENS, 2000, p. 70). Essas e outras questões fizeram com que a Pontifícia Universidade Católica do Paraná - PUCPR ${ }^{1}$, na última metade dos anos 90, iniciasse um processo de reformulação do seu projeto pedagógico. Esse vem coadunado com as grandes tendências em relação à formação superior para o próximo milênio, objetivando dar suporte a uma formação capaz de preparar seus alunos para a sociedade complexa, profundamente alicerçada nas tecnologias da informação e da comunicação, a qual exige, entre outras coisas, uma postura proativa diante do conhecimento e dos desafios que a realidade coloca para os profissionais.

Para o processo de institucionalização dos ambientes virtuais de aprendizagem nos pautamos teórica e metodologicamente neste projeto, o qual tem como um de seus fundamentos o conceito de práxis: Esse conceito compreende três momentos: agir, refletir criticamente sobre a ação e voltar a agir, levando em conta a reflexão feita. (Projeto Pedagógico, 2000, p. 12)

A partir disso, a formação almejada pela instituição é aquela na qual as ações dos professores e alunos encaminhem-se, dentro e fora da instituição, num esforço conjunto.

(...) para superar as tendências existentes na cultura (da importância de ter poder, de aumentá-lo sempre e de permanecer nele) estabelecida nas décadas finais do século XX [pois] parece útil para não escamotear a avaliação crítica do próprio agir, para não reduzir a atuação a uma barbárie racionalizada, com uma roupagem justificadora constituída por diferentes e variados recursos de racionalizações. A práxis, com uma razão crítica, não facilita encobrir ou disfarçar a incoerência entre o discurso e a atuação, entre a realidade e as versões produzidas sobre ela. (Projeto Pedagógico, 2000, p. 13)

Essa filosofia buscou nos paradigmas emergentes da educação, tendo como foco a aprendizagem colaborativa, os fundamentos para a concretização desses objetivos. Neste sentido, os princípios que passaram a nortear as ações na instituição se voltam para a participação ativa dos alunos, com ênfase na aprendizagem processual e individualizada, na busca pela harmonia entre a dimensão técnica e a humanística na formação superior, no desenvolvimento das aptidões técnica e científica, para uma qualificação filo- 
sófica, política e ética, tendo como proposta teórico-metodológica a aprendizagem colaborativa.

Segundo BEHRENS (1999), a aprendizagem colaborativa se assenta sobre quatro pilares: aprender a conhecer, aprender a fazer, aprender a viver junto e aprender a ser.

Neste momento não aprofundaremos esses quatro fundamentos, mas daremos ênfase no imbricamento dessa metodologia com as tecnologias digitais.

Diante dos desafios colocados na busca de um rompimento com a herança trazida ao longo de seus 42 anos de existência, a PUCPR investiu pesadamente nas tecnologias digitais, disponibilizando-as para professores e alunos em horários e espaços de livre acesso. E entre as inúmeras mudanças concretas implementadas para sustentar o Projeto Pedagógico, algumas se mostram nucleares, tais como: a alteração da estrutura curricular (de disciplina para Programa de Aprendizagem), da pesquisa como eixo norteador das atividades educativas, e a ampliação da noção de "sala de aula" para além do espaço físico entre quatro paredes.

Com isso estavam criadas as condições mínimas para que professores e alunos pudessem utilizar as tecnologias digitais para "(...) estimular 0 acesso à informação e à pesquisa individual e coletiva, favorecendo processos para aumentar a interação entre eles." (BEHRENS, 2000, p. 97).

Segundo a autora,

A facilidade da tecnologia da informação proporciona aos alunos acesso a uma quantidade imensurável de informação dentro e fora da universidade. Os alunos como internautas podem acessar as informações disponíveis na rede. Os bancos de dados, os sistemas especializados, os programas educativos e os recursos de multimídia proporcionam informações e experiências que podem complementar, enriquecer, instigar os processos de aprendizagem. A necessidade de entreajuda e a maneira colaborativa podem desenvolver autonomia, espírito crítico e atitude de trabalho coletivo. (idem, p. 101)

Ainda que a aprendizagem colaborativa não prescinda da tecnologia para ser adotada, acredita-se que essa amplifica sua possibilidade e potencializa as situações nas quais professores e alunos, e esses entre si, pesquisem, discutam, se relacionem e construam suas trajetórias individuais e coletivas com 0 conhecimento. Os softwares de exercício e prática, os tutoriais, os jogos, as linguagens, os programas de autoria, os editores de textos, os simuladores e a Internet constituem em si um arsenal que pode auxiliar na mudança de paradigma.

Esses recursos, quando acompanhados de uma proposta metodológica de uso, como realçado por ALCÂNTARA et al. (1999), podem vir a se tornar grandes parceiros na busca de (...) uma nova ação docente na qual professor e alunos particip[em] de um processo conjunto para aprender de forma criati- 
va, dinâmica, encorajadora que tenha como essência o diálogo e a descoberta. (p. 3)

Pois, neste contexto, segundo os autores:

A relação professor-aluno na aprendizagem colaborativa contempla a interrelação e a interdependência dos seres humanos que deverão ser solidários ao buscarem caminhos felizes para uma vida sadia deles próprios e do planeta. Neste processo, empreender projetos que contemplem uma relação dialógica (Freire, 1997) onde os professores, ao ensinarem, aprendem; e os alunos, ao aprenderem, possam ensinar. A relação é de parceiros solidários que enfrentam desafios das problematizações do mundo contemporâneo e se apropriam da colaboração e da criatividade, para tornar a aprendizagem significativa, crítica e transformadora. (p. 3)

Esses princípios e ações construíram a base sobre a qual iniciamos, durante os anos de 1999 e 2000, a institucionalização do ambiente virtual de aprendizagem Eureka ${ }^{2}$ na PUCPR, procurando colocar a tecnologia a serviço da construção de uma prática docente e discente alicerçada sobre uma filosofia humanista e com o suporte dos pressupostos da aprendizagem colaborativa.

Tendo em vista as especificidades do processo, a experiência da PUCPR não pode ser inscrita como uma transformação da educação presencial para a educação à distância, uma vez que adquiriu características específicas, tais como: o uso do ambiente virtual de aprendizagem pode ser feito por qualquer nível (graduação e pós-graduação), partindo de uma iniciativa do professor em querer adotar a ferramenta; não é desenvolvido material especificamente para os momentos não-presenciais, a não ser que o professor queira montar sua Home Page para os alunos, mas fundamentalmente as fontes bibliográficas podem ser as mesmas; a tutoria é feita pelo professor da disciplina, seguindo, dessa forma, o modelo do ensino presencial; as avaliações seguem as sistemáticas do MEC, e todos os processos de avaliação dos cursos continuam seguindo os critérios estabelecidos pelas Comissões de Especialistas das áreas, pelas leis, pareceres e decretos que regulamentam a avaliação do ensino presencial superior. Neste sentido, pelo menos até o presente momento, a institucionalização dos ambientes virtuais de aprendizagem se constitui em uma alternativa tecnológica aos docentes para apoiar suas atividades de sala de aula, pois conforme apontado acima, pode ser uma ferramenta que apresenta novas possibilidades de atividades e experiências de apoio aos momentos presenciais em busca da aprendizagem colaborativa.

\section{Oprooesso}

A partir desses elementos, as atividades educativas, apoiadas na 
virtualização, desenvolveram-se com características inerentes à realidade da instituição. Desde a sua criação não houve obrigatoriedade para que todo 0 corpo docente utilizasse o ambiente Eureka. As iniciativas para a sua institucionalização nasceram do grupo de pesquisadores, professores e estagiários da Coordenadoria de Educação a Distância (CEAD), procurando criar as condições necessárias para as mudanças em direção aos objetivos estratégicos adotados para a década que se iniciava. Os professores foram aderindo ao ambiente virtual de forma gradativa e a partir de um trabalho de divulgação desse grupo. A capacitação que receberam, nesse primeiro momento, se constituiu na elucidação do ambiente, e dos potenciais das ferramentas que 0 sistema disponibilizava (comunicação síncrona e assíncrona, área para textos e outros materiais, cronograma e outras). Ou seja, neste período inicial não ocorreu uma capacitação que se preocupasse com a dimensão teóricometodológica.

Neste sentido, apesar de ser uma das linhas orientadoras do Projeto Pedagógico, a institucionalização de novas metodologias, apoiadas nas tecnologias da informação e da comunicação, a adesão à ferramenta de virtualização partiu de uma iniciativa do docente, a partir das possibilidades apresentadas pelo ambiente Eureka e da vontade individual de experimentar essa nova modalidade de educação. Este dado certamente marcou profundamente os resultados alcançados, pois contrariamente ao que acontece nas grandes instituições ou redes de ensino nas quais as medidas são tomadas centralizadamente e impostas aos docentes, na PUCPR nasceu de uma vontade individual. Em termos mais concretos, o que foi oferecido aos professores foi uma ferramenta para apoiar suas atividades de sala de aula, com possibilidade de desenvolvê-las extra-sala virtualmente, sem, no entanto, abrir mão da carga horária de aula presencial, uma vez que a instituição é regulamentada como de ensino presencial. Apesar de parecer, num primeiro momento, aumento de tarefas para docentes e discentes, trazia uma série de vantagens e novas possibilidades em termos de comunicação e de atividades para esses sujeitos.

Desse processo emergiu muito rapidamente toda uma geração de professores e alunos que passaram a incorporar a virtualização nas suas práticas educativas. Até dezembro de 2000 foram criadas no ambiente $\mathbf{5 0 0}$ salas virtuais, e 8.218 usuários se inscreveram no Eureka, entre alunos de cursos de graduação e pós-graduação da PUCPR, professores e alunos avulsos (participantes de cursos oferecidos pela instituição), além de outros usuários externos ou internos da PUCPR que estavam testando o sistema. As áreas disponibilizadas pelo sistema eram para os cursos de graduação, cursos de pós-graduação, cursos de extensão, grupos de discussão e outros grupos. 
Na tabela abaixo apresentamos a distribuição e o percentual quanto ao tipo de salas abertas:

\section{Tabela 1: distribuição quanto ao tipo de sala}

\begin{tabular}{|c|r|r|}
\hline tipo & No. cit. & \multicolumn{1}{|c|}{ Freq. } \\
\hline graduação & 312 & $62,40 \%$ \\
\hline extensão & 13 & $2,60 \%$ \\
\hline pós-graduação & 40 & $8,00 \%$ \\
\hline grupos de discussão & 48 & $9,60 \%$ \\
\hline outros & 87 & $17,40 \%$ \\
\hline TOTAL OBS. & $\mathbf{5 0 0}$ & $\mathbf{1 0 0 \%}$ \\
\hline
\end{tabular}

Esses dados foram surpreendentes e mostraram a grande aceitação que estava tendo o ambiente no interior da instituição. Em seguida, apresentamos as características do ambiente, o qual disponibiliza para seus usuários os seguintes módulos:

INFO: contém as informações gerais do curso. Nesse módulo também consta a Descrição e o Programa do curso e o Edital, de acesso restrito ao tutor, onde ele pode se comunicar com toda a turma, pois ao entrar na sala, é primeiramente visualizada a mensagem postada pelo tutor.

CHAT: sala de conversa. Permite a comunicação síncrona entre os alunos habilitados na sala e o tutor.

CORREIO: como um correio eletrônico tradicional, alunos e tutores podem criar, responder e excluir mensagens para os integrantes do grupo. Esse módulo é de comunicação assíncrona.

CONTEÚDO: nesse módulo existem dois espaços diferenciados: num deles - Conteúdo - somente o tutor pode disponibilizar materiais tais como textos, imagens, vídeos, ou seja, qualquer arquivo em meio magnético. No outro, denominado de Espaço Aberto, qualquer integrante do grupo pode "pendurar" arquivos. Além dessas duas pastas que o sistema cria automaticamente, alunos e tutores podem criar outras pastas tal como no ambiente Windows, configurando-se como comunicação assíncrona.

ESTATÍSTICA: nesse módulo ficam disponibilizadas informações sobre 0 acesso dos integrantes do grupo às ferramentas em forma de planilhas. É possível visualizar os dados gerais, por usuário, por módulo e por período.

FÓRUM: permite a inclusão de tópicos, com organização em níveis, sobre assuntos a serem discutidos entre alunos e professores. Esse módulo é de comunicação assíncrona.

LINKS: nesse módulo alunos e tutores podem disponibilizar endere- 
ços de sites com acesso direto como sugestão para os integrantes visitarem. É possível incluir comentários, tanto por aqueles que o postaram como por outras pessoas, sobre o conteúdo dos endereços.

PERFIL DOS PARTICIPANTES: ficha cadastral dos integrantes da sala. Na realidade, são as informações dadas pelos usuários no momento em que eles pedem inscrição no ambiente.

AJUDA: sistema de ajuda aos participantes, contém todas as informações sobre 0 ambiente.

CRONOGRAMA: módulo no qual é possível indicar atividades durante o tempo de vigência da sala. As atividades podem ser definidas a partir de um conjunto de descritivos predefinidos e indicado o modo de realização: individual, em equipe ou todo o grupo.

Abaixo segue uma imagem da tela inicial, onde pode ser verificada a extrema simplicidade com a qual o usuário se depara ao entrar no sistema. Este aspecto foi fundamental para o andamento das atividades, uma vez que nesta experiência lidamos com um público muito heterogêneo no trato com a tecnologia, bem como com as ferramentas de comunicação via Internet.

\section{Gráfico 1: tela inicial do sistema}

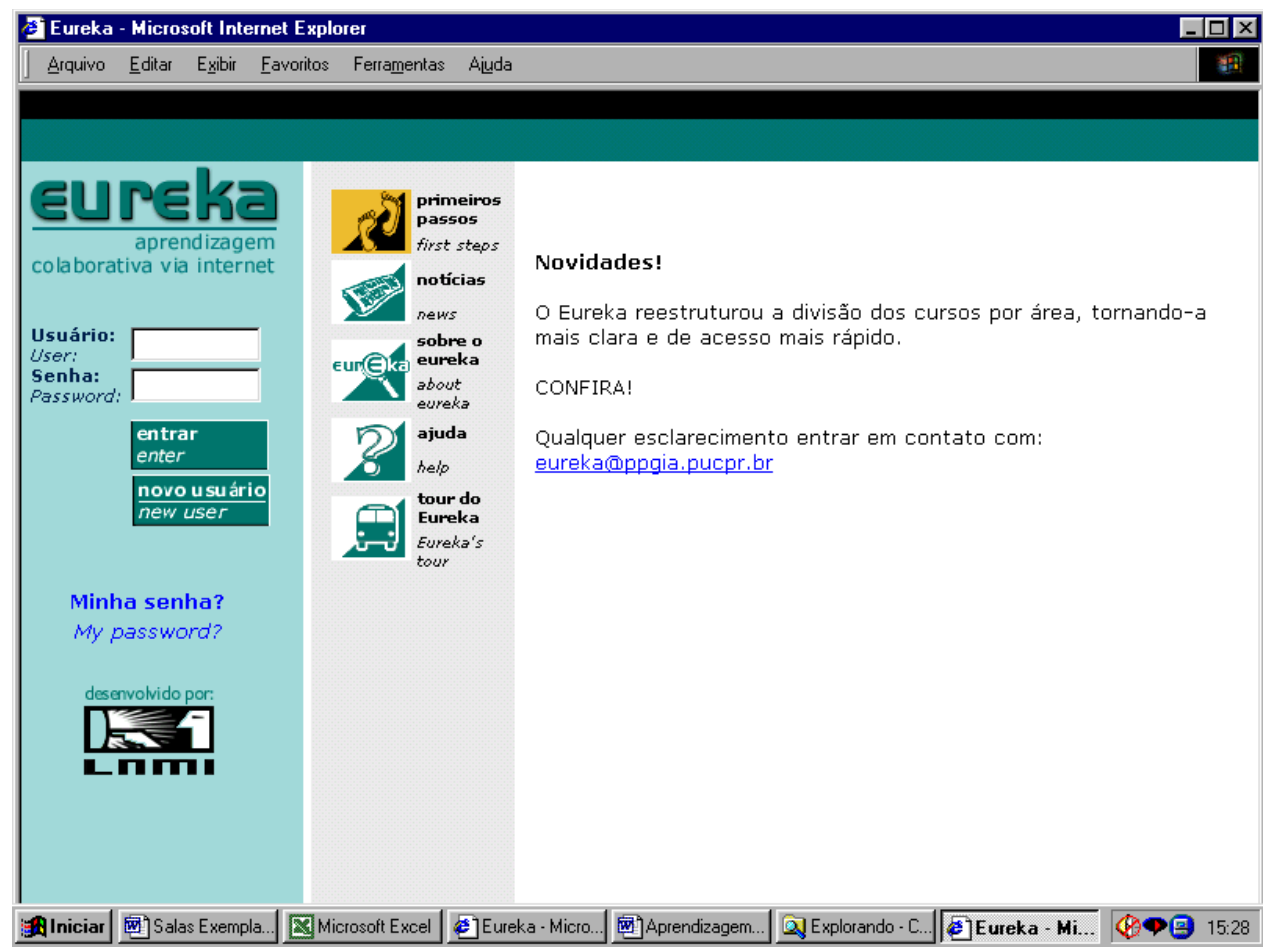




\section{Gráfico 2: tela de entrada de uma sala virtual}

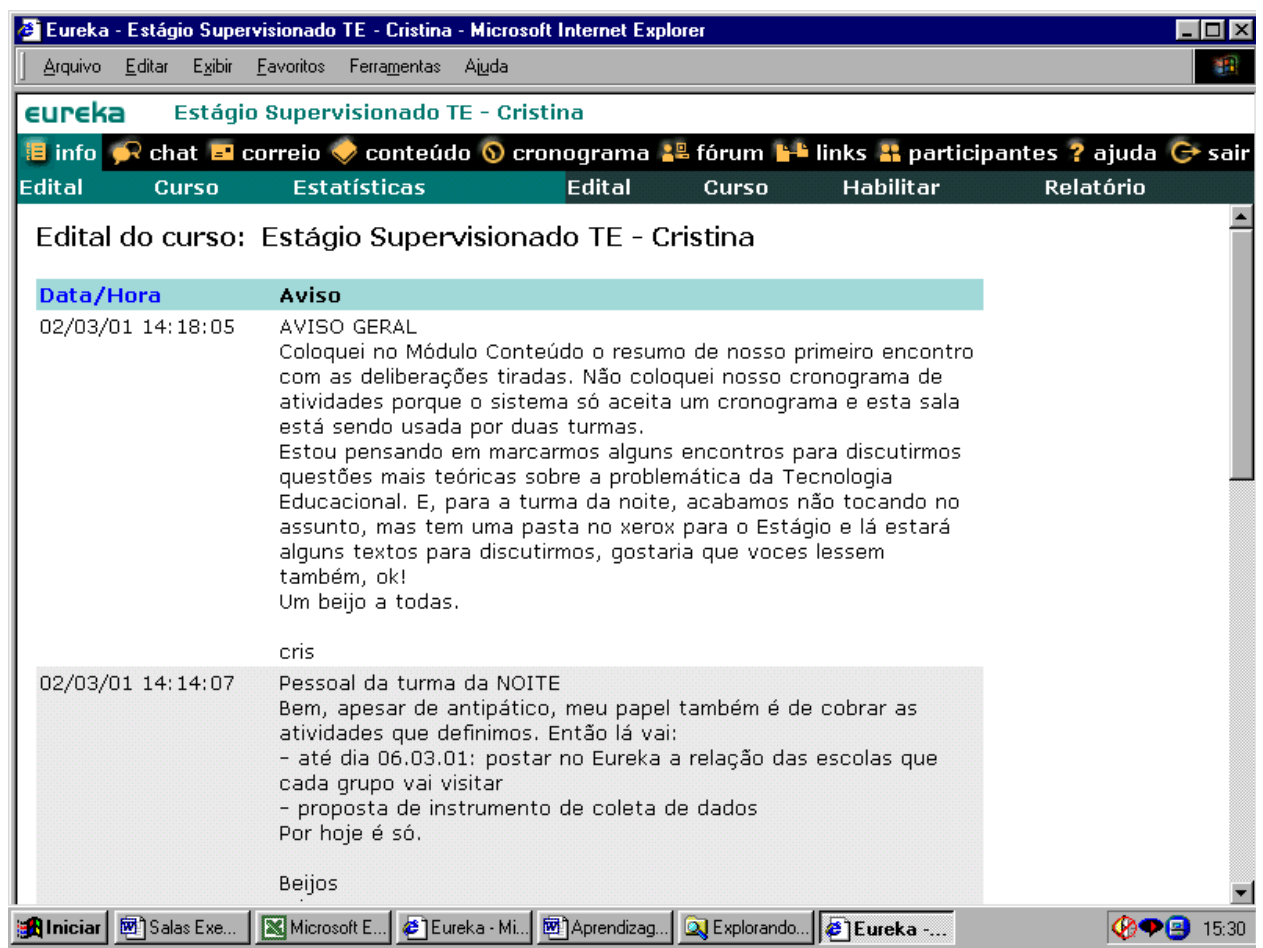

Quanto aos usuários, o Eureka possui três situações: o usuário pode ser um administrador, um tutor ou um aluno. Os administradores do sistema são os responsáveis pela criação das salas e habilitação dos tutores. Esses sujeitos atuam somente no início do processo, disponibilizando o espaço da sala virtual para que os tutores, em sua grande maioria professores da disciplina, possam desenvolver suas atividades. Após esse processo, os administradores normalmente são chamados para resolver problemas de ordem técnica e/ ou metodológica.

Os tutores são os protagonistas da dinâmica da sala virtual. Eles são os responsáveis por habilitar os alunos, alterar ou excluir os dados da sala, como materiais, datas, cronogramas, comentários no Fórum, materiais disponibilizados no espaço reservado ao tutor etc.

E os alunos, uma vez habilitados a acessar a sala, podem interagir com todas as ferramentas, inserir materiais no Espaço aberto, contribuições no Fórum, Links, participar do chat, enviar mensagens pelo correio eletrônico da sala.

Seguindo as orientações teórica-metodológicas do Projeto Pedagógico, o uso do ambiente Eureka se mostrou bastante apropriado. Desde a sua 
criação, esse ambiente teve como proposta criar um ambiente virtual no qual as pessoas pudessem interagir, trocar informações e mensagens. Como colocam seus idealizadores: $\mathrm{O}$ ambiente foi desenvolvido com o intuito de propiciar aos participantes a possibilidade de aprender via colaboração, tanto do professor com o aluno como dos alunos entre si. (Maia, 2000, p. 91)

\section{Análisedos conteúdos das Salas Ex emplares}

Decorrido um ano do processo, ao final de 2000 iniciamos um trabalho de levantamento estatístico e análise quantitativa e qualitativa das salas criadas no ambiente. Seguindo procedimentos metodológicos de coleta e tratamento dos dados delineados pelo grupo de pesquisadores do $\mathrm{CEAD}^{3}$, decidimos investigar com maior acuidade algumas salas que tiveram um uso diferenciado em termos de freqüência e de intensidade de uso dos recursos. Essas salas foram categorizadas como salas Vazias, Esparsas, Medianas e Exemplares. Para o presente artigo apresentaremos uma análise das salas selecionadas na categoria Exemplares, num total de 13 salas, oriundas dos cursos de graduação em algumas áreas do conhecimento.

Cabe ressaltar que, após a pesquisa, identificamos a necessidade de lançar mão de outros instrumentos de pesquisa para melhor elucidar o que ocorreu naqueles espaços virtuais durante o período do curso, tais como entrevistas com professores e alunos, questionários ou mesmo as escalas para identificar opiniões e atitudes do grupo de usuários do sistema. Estes são os próximos passos nesta pesquisa. Portanto, ainda que possamos identificar algumas particularidades na interação de professores e alunos e de alunos entre si nessas salas, muito ainda pode vir à tona após um aprofundamento oriundo das pesquisas com os próprios sujeitos envolvidos na experiência. E, por último, para empreender a análise da amostra selecionada, construímos um instrumento que pudesse identificar alguns aspectos que nos interessavam. Com isso, dos conteúdos impressos, obtidos pelos relatórios das salas, pudemos ter acesso à totalidade do que foi inserido nos módulos Descrição, Edital, Fórum e Link. Do módulo Edital, espaço no qual só o professor pode inserir informações, interessava-nos os Conteúdos dos avisos, se eram avisos gerais com respeito à disciplina, ou com regras do curso, notas, outros avisos sem relação com o conteúdo; a Interação com o aluno, mais especificamente 0 tipo de solicitação de atividade, se houve incentivo a contribuições, se proporcionou divisão de responsabilidades nas atividades, se efetuava intervenção nas contribuições dos alunos, se houve direcionamento das atividades, se propunha interação entre os alunos sobre o curso e se procurava estabelecer uma relação mais democrática ou autoritária. Ainda nesse módulo, analisamos as Atividades propostas, se possuíam forte relação com os conteúdos, se 
essas buscavam apoiar os momentos presenciais, se solicitavam pesquisa por parte dos alunos, se exigiam ou estimulavam a interação entre os alunos, se as fontes solicitadas extrapolaram o ambiente virtual.

Do módulo Fórum, preocupamo-nos em identificar aspectos ligados ao próprio teor das Discussões, dos tópicos colocados e sua relação com o conteúdo da disciplina, da qualidade da intervenção do aluno, e do tipo de intervenção do professor. Ainda procuramos perceber qual a Interação entre os alunos, principalmente na relação das contribuições com o conteúdo, se houve incentivo em participar do debate, a homogeneidade do grupo no que diz respeito à quantidade de intervenções. E, finalmente, nesse módulo coube investigarmos sobre a Atuação do docente, se atuava sobre os debates como membro ou como autoridade, se intervinha no direcionamento dos tópicos/ debates, se propôs atividade variada, se garantiu síntese dos debates.

Para o módulo Link, cabia verificarmos quanto à Indicação do link, ou seja, quem indicou (professor ou aluno); e quanto ao Tipo de link, se esse tinha relação com a disciplina, bem como os comentários sobre ele. Foi com base nesses conteúdos e observando esses aspectos que procedemos à análise exposta abaixo.

\section{Análise do módulo Edital}

Conforme explicitado acima, esse espaço é destinado fundamentalmente à explicação da metodologia de trabalho, apelidado de Mural Eletrônico, sobre qual atividade será desenvolvida, os critérios de avaliação e outras informações que o tutor queira disponibilizar para todo o grupo. Em síntese, esse espaço pode ser definidor da dinâmica de relacionamento entre o professor/tutor com os alunos.

$\mathrm{Na}$ análise realizada das salas Exemplares, constatamos que quanto aos conteúdos dos avisos, seguiam, com poucas exceções, uma característica comum: de se prenderem muito fortemente às questões relativas ao andamento das atividades do curso, com avisos de atividades, normas e regras a serem seguidas, tal como se estabelecem nos primeiros dias de aula, quando o professor entra em sala e apresenta seu programa e a dinâmica que deverá ser seguida. Especificamente no quesito interação com os alunos, observamos que $50 \%$ dos professores fizeram uso do edital de forma positiva, utilizando a ferramenta (ou módulo edital) para incentivar seus alunos a colaborar, a contribuir e interagir com o ambiente, com situações nas quais os professores interagiram de forma aberta e convidativa, chamando os alunos a participarem, utilizando inclusive brincadeiras, num clima de cooperação e respeito. Nas atividades houve incentivo à busca de outras fontes para pesquisa e ao esclarecimento das dúvidas referentes ao uso do ambiente, mas na grande 
maioria das salas as atividades ainda se constituíam naquelas já desenvolvidas pelos alunos na sala de aula: trabalhos e exercícios de livros, atividades em grupo que pressupunham o encontro presencial entre eles etc. Os outros 50\% utilizaram o edital simplesmente como um espaço de divulgação, sem procurar, por meio dele, promover interação ou cooperação entre os alunos e entre ele e seus alunos.

Com base nessas questões observadas, cabem algumas considerações quanto à forma como foi utilizado. Nesse módulo (edital) o professor qualifica suas informações, uma vez que o edital pode ser considerado 0 "cartão de visita" da sala virtual perante o grupo. Com isso pudemos observar, considerando que caberia uma investigação mais aprofundada, que o relacionamento desse com o grupo transparece numa certa medida pela linguagem que ele utiliza, pela maneira como ele se posiciona perante o grupo: como autoridade ou como parceiro, uma vez que somente o professor pode disponibilizar mensagens que poderão influenciar as dinâmicas relacionais. Nos pautamos para fazer essas considerações na relação que evidenciamos entre os conteúdos das mensagens postadas, na forma em que foram disponibilizadas, na linguagem adotada e na predisposição mostrada pelos alunos em participar e contribuir nos outros módulos, bem como na qualidade das intervenções dos mesmos. Pudemos levantar fortes indícios de que um uso diferenciado do Edital promoveu uma participação mais qualificada, do ponto de vista inter-relacional, entre os alunos entre si e desses com o tutor.

Por outro lado, uma característica observada foi que, ainda com algumas exceções, os tutores se apoiaram na avaliação, na nota, como estímulo para os alunos participarem no ambiente. Isso nos aponta para a dificuldade de se romper com um modelo de relacionamento e de práticas. Ainda que se tenha boa vontade para mudanças drásticas, ela se dá por pequenas rupturas, gradativamente rompendo com os laços que a prendem ao passado. $\mathrm{O}$ fato dos professores se utilizarem da nota como estímulo é uma prática muito antiga, e ainda central no processo educacional e, por certo, permaneçará nos cotidianos das salas de aula virtuais ou não.

Um outro aspecto que pudemos depreender: as atividades se desenvolveram continuamente ao longo dos semestres do ano letivo, seu uso não se deu porque significava uma nova experiência, não foi um uso impulsivo, mas de experimentação de uma nova ferramenta e metodologia de trabalho, o que consideramos um aspecto positivo.

\section{Análisedo uso do FórumdeDiscussões}

O módulo Fórum é destinado a discussões abertas, podendo ser organizadas em diversos níveis. Trata-se de uma ferramenta de conversação 
assíncrona que permite estabelecer uma dinâmica comunicacional com os participantes da sala, permitindo visualizar todas as contribuições postadas pelos integrantes do grupo. Com isso, seu uso mais adequado, segundo o projeto do sistema, é para aprofundar um tema, abrir discussões novas, ou simplesmente discutir outros assuntos não necessariamente ligados aos conteúdos. Esses usos, em boa medida, são delineados pelo tutor, na forma como ele intervém nas discussões que estão ocorrendo na sala.

$\mathrm{Na}$ análise realizada das salas Exemplares, o uso do Fórum se caracterizou por discussões apoiadas no conteúdo dos cursos, e até superando-os. No entanto, existiram salas em que ocorreu um uso diferenciado, servindo ora como e-mail ora como escaninho virtual dos professores, para que os alunos postassem respostas às questões ou exercícios solicitados pelo tutor.

Diante desse uso, levantamos algumas questões. Pela dificuldade de impressão dos trabalhos postados no Fórum, perguntamo-nos se foi conveniente aos professores a leitura na tela das respostas, muitas vezes bastante longas dos alunos, e uma de cada vez, sem possibilidade de comparar uma com a outra. Como os professores avaliaram comparativamente o conteúdo das contribuições? Foram feitas sínteses dessas contribuições virtualmente ou presencialmente? Qual o objetivo do professor ao utilizar a ferramenta com essa estratégia - "escaninho virtual"? Essas questões sugeriram que o uso da ferramenta está sendo feito de formas diversas àquelas planejadas inicialmente. Isso pode ter aspectos positivos e negativos: positivamente, uma vez que está havendo uma apropriação do ambiente dentro de estratégias individuais de trabalho, o que delineia uma certa flexibilidade do sistema na interação com o usuário. Negativamente, pois a ferramenta pode estar sendo, inconscientemente por parte de professores e alunos, subtilizada ao não funcionar como espaço de debate, discussão e síntese, mas se resumindo num repositónio de trabalhos com pouca ou nenhuma intervenção do professor e interação com os alunos entre si.

Houve somente uma exceção, muito interessante, na qual o profes-

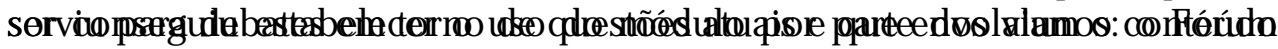
trabalhado em sala de aula. Nessa experiência pudemos observar uma grande participação dos alunos, interagindo entre eles, trazendo informações para subsidiar os debates. Ainda que o professor tenha adotado uma estratégia de pouca intervenção, talvez por preferir fazê-la em sala, como pudemos depreender pelas referências feitas pelos alunos a discussões em outros espaços (sala de aula?). Neste caso em particular, caberia uma investigação mais aprofundada para verificar essa teia de relações que se estabeleceu e identificar o papel que cumpriu a sala de aula virtual nesse processo e se apresentou potencial para dar conta das necessidades do grupo.

Diante dessa análise temos, por um lado, que considerar a possibilidade da ferramenta não estar apoiando a Aprendizagem Colaborativa tal como 
definida anteriormente, mas trazendo limitações a ela. Por outro lado, temos que considerar a possibilidade de que o que ocorreu foi a reprodução de velhas práticas, tanto por parte dos professores quanto dos alunos, numa adequação da ferramenta a um modelo já praticado. Se isso realmente se configurar, ainda que tenhamos clareza de que a tecnologia é um suporte, caberia repensar o quanto o ambiente virtual propicia um espaço adequado ergonomicamente, comparativamente à sala de aula, para o desenvolvimento da Aprendizagem Colaborativa. Temos clareza de que são experiências iniciais e que as características do processo na PUCPR, diferentemente de outras experiências brasileiras, incluem a complexidade do fazer pedagógico, das problemáticas comunicacionais e educacionais que permeiam os espaços concretos de sala de aula ao propor uma simbiose entre o presencial e o virtual.

\section{Análise do módulo Link}

Nesse módulo é possível criar uma biblioteca eletrônica com links de interesses correspondentes aos assuntos tratados na sala virtual. Na análise das salas Exemplares pudemos observar que houve uma participação homogênea na disponibilização de link, tanto do tutor quanto dos alunos, bem como predominaram sites que possuíam forte relação com o conteúdo do curso. Entretanto, houve muito pouco comentário sobre os endereços. Isto pode nos indicar duas questões: ou os sites não foram visitados pelos colegas ou seu conteúdo não foi significativo o suficiente.

Deste aspecto identificado fizemos algumas considerações quanto ao uso da Internet como espaço de ampliação das fontes de pesquisa. Levantamos a hipótese de que pode estar havendo ainda, por parte de alunos e professores, um certo desconhecimento quanto à metodologia de busca na Internet. Ou seja, sabemos que na operacionalização de pesquisa na Internet, se não for utilizada uma boa estratégia, podemos encontrar endereços que pouco contribuem, seja porque o assunto tratado não é significativo para a situação, seja porque seu conteúdo é questionável. Se não houver domínio metodológico, pesquisar na Internet pode se transformar numa grande frustração e num trabalho insano, tendo em vista as proporções que a rede assumiu nos últimos anos. E, ainda assim, mesmo com as facilidades de acesso a informações oferecidas pela Internet, podemos estar lidando com uma questão cultural: de maturidade dos alunos, na pesquisa e leitura de textos, de imagens etc; e dos professores, em acreditar que coisas boas possam ser encontradas na rede. A seguir colocamos alguns dados numéricos para melhor dimensionar o uso do módulo Link. 


\section{Gráfico 3: percentual quanto à indicação dos links.}

\section{Quanto à indicação dos Links}

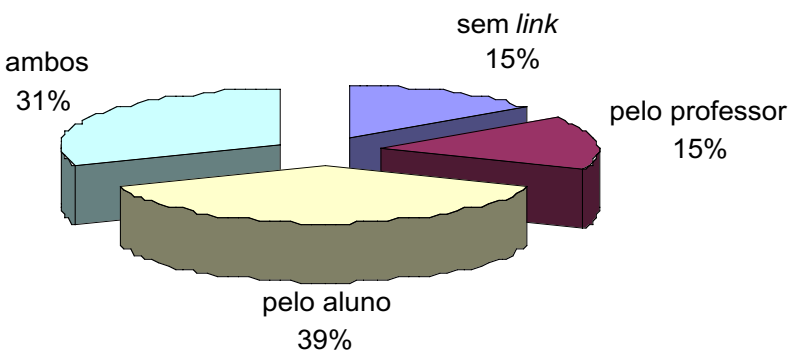

No gráfico acima, temos que em $85 \%$ das salas houve indicação de links, sendo que $39 \%$ somente pelos alunos, $15 \%$ somente pelos professores e $31 \%$ por ambos. E, ainda, dessas salas com indicação de links, em $62 \%$ delas os alunos fizeram comentários sobre o conteúdo dos sites e em $32 \%$ não houve comentários.

Gráfico 4: percentual quanto à ex istência de comentários sobre os sites.

Quanto à existência de comentários sobre os sites.

sem

comentários

$38 \%$

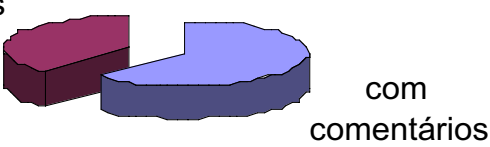

$62 \%$ 


\section{Considerações "iniciais"}

Esta experiência nos trouxe muitas incertezas, mas também uma grande certeza: a questão da virtualização (total ou parcial), dos ambientes de aprendizagem na educação, pelo menos em nível superior, passa necessariamente pelas questões ligadas à prática pedagógica desenvolvida pelo docente ao longo de sua vida profissional. Isto nos remete a duas questões: nosso compromisso como educadores e pesquisadores em educação em estreitar as relações com os grupos de desenvolvedores de ambientes e softwares para a educação e um aprofundamento em termos de pesquisas e propostas metodológicas de educação mediadas pelos Ambientes Virtuais de Aprendizagem. Muitas das experiências analisadas nestas salas podem ser consideradas absolutamente revolucionárias do ponto de vista metodológico, e ainda outras com grande potencial de vir a ser considerada como tal. Não podemos, apesar das ressalvas e observações, desconsiderar o grande esforço desses professores e alunos que buscaram um caminho diferenciado na construção do conhecimento em nível de graduação, esforços esses muitas vezes não compreendidos ou mal dimensionados por aqueles que estão alheios ao processo. É isso que nos move a continuar investindo nessa tecnologia e na implementação de novas propostas metodológicas para a educação na PUCPR. Ao avaliar as características do processo ocorrido na PUCPR, concluímos que tivemos ganhos imensos e grandes avanços, mas ainda temos muito a percorrer. Ainda que as distâncias e o tempo sejam quase superados no ciberespaço, o tempo psicológico requerido para mudanças de hábitos, costumes e de práticas e 0 espaço para as relações humanas ainda estão muito alicerçados na vivência com o real. Assistimos nessa experiência a reproduções e superações, mas também tivemos indícios de que os ambientes virtuais de aprendizagem podem promover a aprendizagem colaborativa. Novos estudos deverão indicar 0 grau de equilíbrio desejado entre esses dois espaços - virtual e o real - para efetivamente transformarmos a educação, que tanto reclama por mudanças qualitativas.

\section{Notas}

1 Alguns dados sobre a instituição: a Pontifícia Universidade Católica do Paraná - PUCPR tem perto de 18.000 alunos divididos em dois campi. Oferece 48 cursos de graduação, 58 de pós-graduação Lato Sensu, 9 de pós-graduação Stricto Sensu. Possui um corpo docente de 1.241 professores, sendo que $53 \%$ são doutores, $36 \%$ mestres e $11 \%$ especialistas e graduados. Em termos de infra-estrutura de informática, possui vários laboratórios conectados na internet em todos os 6 blocos didáticos, além daqueles disponibilizados no setor administrativo, com equipamento Pentium 200 ou superior, impressoras, scanners etc.

2 Para acessar o site: http://www.lami.pucpr/ eureka 
3 Para tanto ver: VARELLA, Péricles et al. Relatório Técnico de Avaliação do Ambiente Virtual de aprendizagem Eureka na PUCPR no ano de 2000, Curitiba, 2001.

\section{Referências Bibliográficas}

ALCÂNTARA, Paulo et al. Aprendizagem colaborativa com tecnologias interativas: Projeto PACTO. Projeto de pesquisa, Curitiba, 2000.

AMERICAN ASSOCIATION FOR THE ADVANCEMENT OF SCIENCE. Science for All Americans: Project 2061 (p.148). New York: Oxford University Press, 1989.

BEHRENS, Marilda A. O paradigma emergente e a prática pedagógica. Curitiba: Champagnat, 1999.

GRAVES, L N. Creating a community context for cooperative learning. In S. Sharan (Ed.). Handbook of cooperative learning methods, 1994.

MAIA, Carmem. (Org.). EAD.BR: educação a distância no Brasil na era da Internet. São Paulo: Anhembi Morumbi, 2000.

VARELLA, Péricles; VERMELHO, Sônia Cristina; HESKETH, Camile; SILVA, Ana Carolina C. Relatório Técnico de Avaliação do Ambiente Eureka na PUCPR. Curitiba: 2001. 